\title{
Revisiting the Data from the New Family Structure Study: Taking Family Instability into Account
}

\author{
Michael J. Rosenfeld \\ Stanford University
}

Abstract: This analysis revisits recent controversial findings about children of gay and lesbian parents, and shows that family instability explains most of the negative outcomes that had been attributed to gay and lesbian parents. Family transitions associated with parental loss of custody were more common than breakups of same-sex couples among family transitions experienced by subjects who ever lived with same-sex couples. The analyses also show that most associations between growing up with a single mother and later negative outcomes are mediated by childhood family transitions. I show that many different types of childhood family transitions (including parental breakup and the arrival of a parent's new partner) are similarly associated with later negative outcomes.

Keywords: family instability; nontraditional families; children's outcomes; gay and lesbian parents

Citation: Rosenfeld, Michael J. 2015. "Revisiting the Data from the New Family Structure Study: Taking Family Instability into Account." Sociological Science 2: 478-501.

Received: April 17, 2015

Accepted: June 11, 2015

Published: September 2, 2015

Editor(s): Kim Weeden

Dol: $10.15195 / \mathrm{v} 2 . \mathrm{a} 23$

Copyright: (C) 2015 The Author(s). This open-access article has been published under a Creative Commons Attribution License, which allows unrestricted use, distribution and reproduction, in any form, as long as the original author and source have been credited. (C) (i)
$T^{\mathrm{N}}$ this paper, I revisit Mark Regnerus's (2012a; 2012c) studies of children whose 1 fathers had ever had a boyfriend, or whose mothers had ever had a girlfriend, based on the New Family Structure Study (NFSS) (Regnerus 2012b). Regnerus (2012a) created a storm of controversy (Gates 2012; Perrin, Cohen, and Caren 2013; Cheng and Powell 2015). Regnerus claimed that children whose parents were gay or lesbian had much worse social, psychological, economic, and legal outcomes compared to children raised by intact biological families.

I analyze data from the New Family Structure Study in several ways. First, I replicate Regnerus's findings using Regnerus's assumptions and data choices, and then I introduce family transitions as a control in the models-a control that Regnerus ignored. I show that most of the associations between negative outcomes and lesbian mothers and gay fathers are rendered insignificant when childhood family transitions are taken into account. Second, I generate a negative outcome index from Regnerus's outcome variables, and I show that both same-sex couple parents and single mothers are weakly or not at all associated with negative adult outcomes after childhood family transitions are taken into account. Third, I leverage the NFSS childhood family calendar to explore the different types of childhood family transitions and their associations with negative adult outcomes.

\section{Family Structure and Family Instability}

In Regnerus's (2012a; 2012c) analyses of the NFSS data, he defined the comparison group as "Intact Biological Families," a category defined by family structure (two biological parents, married to each other), but also by "intactness," or family stability: 
intact biological families were defined by Regnerus to have suffered no breakups or family transitions. NFSS subjects from other family categories, such as lesbian mothers and single mothers, experienced an average of several family transitions each, as I show below. Early critics (Burroway 2012; Gates 2012; Umberson 2012) of Regnerus (2012a) argued that Regnerus's results were biased by his failure to include family instability as a control in his models; I test the family instability critique with NFSS data for the first time.

Regnerus's NFSS papers are examples of arguments in support of the family structure hypothesis. The family structure hypothesis explains children's outcomes based on the presumed differential abilities of different family structures to socialize children. Two-parent families, for example, have resource advantages (in income and time) over single-parent families (McLanahan and Sandefur 1994). Regnerus and others have extended the family structure hypothesis to argue that same-sex couples (only one of whom can be biologically related to each child) have insufficient biological relatedness to children, and that the absence of the second-gender parent deprives children of role models from both genders (Alvaré 2005; Regnerus 2013).

The family instability hypothesis (Kurdek, Fine, and Sinclair 1995; Potter 2012; Fomby and Cherlin 2007) argues that changes in family structure, rather than family structure types, are what matter to children's development. The family instability hypothesis notes that each change in family structure upsets children's established routines and expectations and can lead to anxiety among children. Early descriptive research on divorce and remarriage focused on the ways in which new adults in the house might, unwittingly, disrupt the children's wellbeing. Hunter and Schuman (1980) described a variety of challenges children might face in a reconstituted household, including role confusion and ambiguity, boundary problems, loyalty conflicts (because children sometimes see loyalty to the new parent as disloyalty to the departed parent), and suspicion and doubt arising from the unfamiliar behaviors of the new parent (see also Cherlin 1978; Brody, Neubaum, and Forehand 1986).

Proponents of the family instability hypothesis argue that instability in the family of origin (measured by the number of family transitions in the family of origin) dominates family structure as an explanatory factor in children's outcomes (Wu and Martinson 1993; Wu 1996; Manning and Lamb 2003; Cavanagh and Huston 2006; Fomby and Cherlin 2007; Potter 2012; but see also Carlson and Corcoran 2001; Aughinbaugh, Pierret, and Rothstein 2005). If family transitions are as powerful an independent predictor of negative outcomes as the family instability literature argues, then ignoring family transitions could lead to exaggerated claims about the inherent benefits of one family type over others.

Family instability is not, of course, randomly distributed among families. Parents with substance abuse problems, psychological problems, or personality disorders are more likely to have the kind of turbulent family lives that include many family transitions. Because the NFSS data are retrospective, and because little or no information is available in NFSS about how parental characteristics might have influenced the family transitions that subjects experienced as children, the NFSS data have important limitations. Despite these limitations, the data also have advantages over other data sources due to the especially detailed childhood family calendar in NFSS, which I describe below. 
Hypothesis 1. Childhood family instability will explain most or all of the negative outcomes that Regnerus (2012a; 2012c) attributed to gay fathers and to lesbian mothers.

Hypothesis 2. Childhood family instability will explain most or all of the negative outcomes associated with being raised by single mothers.

If childhood family transitions have explanatory power over adult outcomes sufficient to mediate the association between childhood family structure and negative outcomes, then hypothesis 3 and corollary 3 a follow:

Hypothesis 3. The count of childhood family transitions by itself is a strong predictor of a wide range of adult outcomes.

Corollary 3a: Childhood family transitions will remain a significant predictor of negative adult outcomes even after controlling for childhood socioeconomic status, parental education, childhood family structure, and other factors.

The ability of family transitions to explain the differences in negative outcomes between family structure groups depends on family transitions being associated with family structure. In fact, subjects in the NFSS data who ever lived with a same-sex couple or with a single mother experienced a relatively high number of childhood family transitions, as I document below. Regnerus's (2012c; see also Allen, Pakaluk, and Price 2013) counterargument to the family instability hypothesis is that same-sex couples and single mothers have unstable romantic lives, and the (presumed) greater instability is the reason that children of same-sex couples and single mothers appear to have worse outcomes than other children. Following Regnerus (2012c):

Counter-Hypothesis 4: The instability of nontraditional romantic unions is the prime contributor to the family instability experienced by children in nontraditional families.

\section{Definitions, Data, and Methods:}

The NFSS (Regnerus 2012b) is a cross-sectional representative online survey, with retrospective questions about family of origin and adult outcomes, fielded by survey firm Knowledge Networks/GfK (KN) in late 2011 and early 2012. Subjects in the online panel were recruited by random-digit dialing phone surveys and by address-based sampling. Subjects who did not have Internet access at home were given Internet access. KN screened 15,058 subjects, and respondents raised in nontraditional families were oversampled. Of these subjects, 2,988 (age 18-39) completed the NFSS survey.

Of subjects in the KN panel who were asked to complete the NFSS survey, 48 percent did complete the survey. Factoring in the response rate of 32.6 percent to the initial KN panel (Callegaro and DiSogra 2008), the cumulative response rate in NFSS would be less than 20 percent (American Association for Public Opinion Research 2011). Couper (2000) found that the ability of web surveys to gather information from respondents at every recruitment stage largely overcame the problem of low overall response rate. The $\mathrm{KN}$ representative online methodology has been experimentally tested and found to perform well (despite low response rates) compared 
to other nationally representative survey modes (Chang and Krosnick 2009; Fricker et al. 2005). Regnerus (2012a) showed in an appendix that the weighted NFSS data not only matched the Current Population Survey (CPS) data in basic demographics (which is not surprising, since the NFSS weights are designed to match the CPS demographics), but also that weighted NFSS data closely approximated the sexual behavior and church attendance data from the National Longitudinal Survey of Adolescent Health and from the National Survey of Family Growth. Regnerus's appendix showed that the weighted NFSS had more poor people and fewer people in excellent health compared to other nationally representative surveys, so I reweighted the NFSS to match the health and income cross-tabulation of the 2011 CPS. The re-weighted results (see Table A7 in the appendix) yielded the same substantive findings as the main results weighted by built-in NFSS weight "weight4," so I used weight 4 as the probability weight throughout the analyses.

For my replication of Regnerus's results, I use the same 31 outcome variables that Regnerus (2012a) found to be significantly associated with "gay fathers" or "lesbian mothers," with or without demographic controls, in his Tables 1-4 (see appendix Table A1 for descriptions of the outcome variables). Regnerus found that 22 of these 31 outcomes were associated with subjects raised by single parent families. The 31 outcomes vary widely: from socioeconomic (educational attainment, current household income); to psychological (depression, attachment to others, suicidal ideation); to childhood traumas (sexual contact by parents or adult caregivers); to legal and behavioral (arrests, convictions, marijuana use); to measures of relationship quality and type (cohabitation, exclusive heterosexuality, current relationship quality, number of male partners, number of female partners). Most of the 31 outcomes have unambiguous polarity with respect to individual health and welfare (for example suicidal ideation, income, number of arrests). A few outcomes are ambiguous (TV-watching, cohabitation, exclusive heterosexuality, number of sexual partners).

I standardized (mean zero, variance one) the unambiguous outcomes with the fewest missing values and then combined them into a negative outcome index and standardized the index so that the negative outcome index has mean of zero and variance of one. The negative outcome index has 19 components and a Cronbach's alpha of 0.78 . The 19 negative outcomes that contribute to the negative outcome index are listed in Table A1 in the appendix and include all the most serious negative outcomes (suicidal ideation, currently on welfare, arrests, convictions, sexual contact by parents or adult caregivers, poor health, depression, lacks attachment to others, smoking, marijuana use, unemployment). The negative outcome index does not include the ambiguous outcomes (TV-watching, cohabitation, exclusive heterosexuality, number of sexual partners), and the index also does not include the outcomes with many missing values (e.g., current relationship quality was missing for subjects who were not in a current relationship).

Burroway (2012) argued and Cheng and Powell (2015) demonstrated that Regnerus's (2012a) family categories ("lesbian mothers," "gay fathers," "divorced parents," and "step-parents," among others), were overlapping, and that Regnerus's assignment of cases between the groups was arbitrary. In my replication of Regnerus's results I am constrained to use the same categories he used, but I shift in 
Table 1: New Variables Used in Analysis of the New Family Structures Study data

\begin{tabular}{lllrrr}
\hline & Mean & SD & N & Min & Max \\
\hline Years lived w/ same-sex couple parents & 0.019 & 0.40 & 2988 & 0 & 18 \\
Years lived w/ same-sex couple (if years >0) & 3.7 & 4.1 & 75 & 1 & 18 \\
Years lived w / Single Mother & 3.23 & 5.90 & 2988 & 0 & 18 \\
Years lived w / Single Mother (if years>0) & 9.72 & 6.46 & 1296 & 1 & 18 \\
Years Lived w / Both Biological Parents & 11.64 & 7.91 & 2988 & 0 & 18 \\
Number of Childhood Family Transitions & 1.87 & 3.28 & 2988 & 0 & 33 \\
Family Transitions Subset: breakups of biological parents and & 0.32 & 0.61 & 2988 & 0 & 6 \\
breakups of other heterosexual parenting couples & & & & & \\
Negative Outcome Index, Standardized & 0 & 1 & 2466 & -1.84 & 4.73 \\
\hline
\end{tabular}

Source: NFSS.

Notes: All numbers weighted by “weight4." Maximum N=2988.

subsequent analyses to definitions of exposure to family structures that are based on years lived by each subject in each family structure; these definitions require no arbitrary assignments and better reflect the exposure of each NFSS subject to the relevant family structures of their childhoods.

Cheng and Powell (2015) identified three subjects from Regnerus's lesbian mother or gay father category whose survey answers were internally inconsistent (one subject claimed to be more than seven feet tall and weigh less than 100 pounds; two others finished the survey in an unrealistically short time). None of these three subjects ever lived with same-sex couple parents according to the NFSS childhood family calendar, so they do not influence any results below other than my replications of Regnerus's results. The influence of noise is always greater in less common subpopulations of surveys, which has led to difficulties in identifying same-sex couples not only in NFSS but in larger and more established surveys such as American Community Survey (Gates 2009).

Table 1 shows the weighted average of years lived with both biological parents together (from year one to year 18 of childhood) is 11.64 years. The weighted average of years lived with a single mother (meaning no husband or partner of the mother was present) is 3.23 years out of 18 years of childhood. Regnerus identified 236 gay or lesbian parents, defined as mothers who ever had a girlfriend or fathers who ever had a boyfriend, regardless of whether the same-sex partner ever lived with or even knew the study subject as a child. ${ }^{1}$ Of these 236 lesbian mothers or gay fathers, only 75 were in same-sex unions that the study subjects lived with as children. Among the 75 respondents who ever lived with same-sex couple parents, the weighted average coresidence with same-sex couple parents was 3.7 years, meaning that even for the 75 subjects who ever lived with same-sex couple parents, most of their childhoods were spent being raised by family structures other than same-sex couples. ${ }^{2}$ Because of the difficulty of identifying substantial numbers of children raised by same-sex couples in national surveys, most of the previous studies of children raised by same-sex couples have been small-N convenience sample studies (Meezan and Rauch 2005; Stacey and Biblarz 2001), with a few 
exceptions predicting the grade school progress of children raised by same-sex couples (Potter 2012; Rosenfeld 2010).

I define cumulative family transitions to include the sum of all changes in yearto-year parental structures in the calendar listings from the NFSS subjects' childhood family calendars (see the illustrative examples in Table 2, below). Subjects were asked to "Please select the ages when you lived with the following persons..." and were shown a matrix with 13 potential household members ${ }^{3}$ plus the following living arrangements: "institution," "foster parents," "on your own," and "other," by 19 years (from birth to age 18), plus "always." Subjects who as children were moved from one household to another can have accumulated many childhood family transitions, which accounts for why the maximum value for childhood family transitions among NFSS subjects is 33 . Across the 2,988 adult subjects in the NFSS, the weighted average number of childhood family transitions for each subject's 18 years of childhood is $1.87 .^{4}$

Other data-sets have childhood family calendars that have been used to account for childhood family transitions. Cavanagh (2008) used the National Longitudinal Study of Adolescent Health, Wave 1, and reported that subjects had 0.62 family transitions, on average, by age 15. Wu and Martinson (1993) used the National Survey of Families and Households and found an average of approximately 0.7 childhood family transitions per subject. Potter (2012) used the Early Childhood Longitudinal Study, Kindergarten cohort, and found an average of 0.53 family transitions by the time children were in eighth grade. The NFSS count of total childhood family transitions is 1.87 on average and is therefore larger than the count of childhood family transitions from prior data sources, in part because the NFSS childhood family calendar covers a broader set of family structures, including the same-sex couple parents which are crucial for Regnerus's paper and for my replication, along with separate year-by-year boxes for coresidence with grandmothers, grandfathers, other relatives, foster parents, and so on. I show below that a narrower definition of family transitions, based on parental breakups and more consistent with the measures of family transitions that other scholars have used, predicts negative outcomes much less well than the broader measure of family transitions predicts negative outcomes.

The skewness of the distribution of family transitions means that there are outliers in the family transition distribution. Figure 1 shows that the relationship between family transitions and the negative outcome index (a relationship I explore below) is not driven by outliers. The family transition subset that covers only heterosexual parent breakups has a much lower average, 0.32 , and a maximum of six.

The year-by-year childhood family calendar in NFSS enables a cumulative accounting of each subject's years of exposure to each family structure type (including same-sex couples), and also a cumulative accounting of family transitions. The calendar is centered around coresidence with the subject when the subject was a child. Because NFSS provides no information about the adults in the child's life who were not coresident with the child, the nature and longevity of the romantic relationships of non-coresident parents are unknown. 


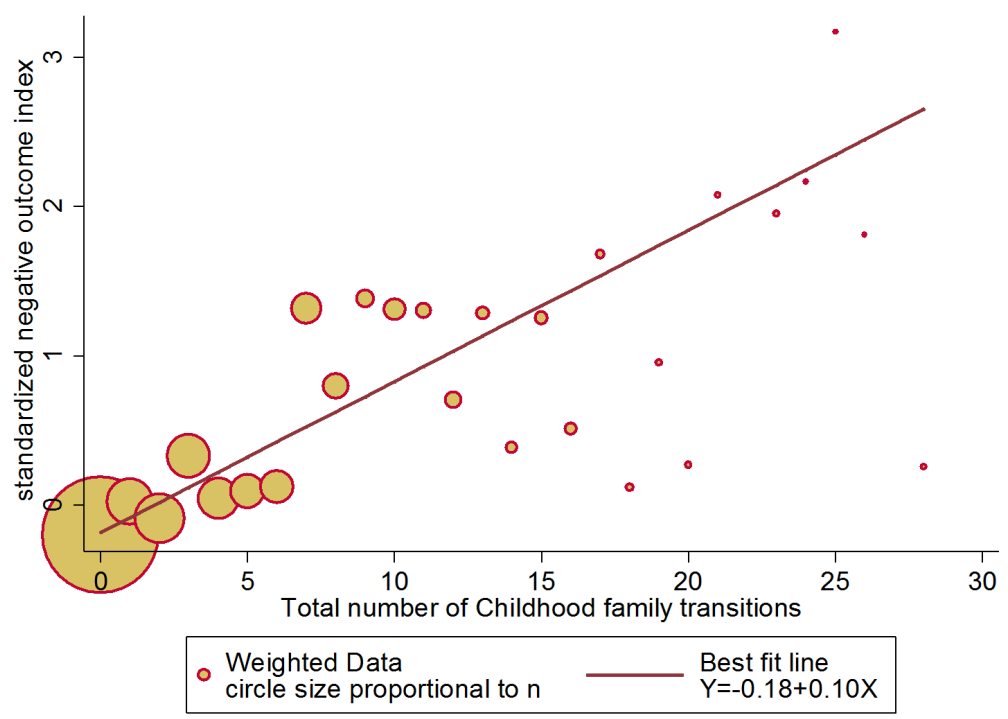

Figure 1: Negative Outcome Index as a Function of Childhood Family Transitions Source: NFSS data, weighted by "weight4." $\mathrm{N}=2,466$.

Logistic regressions were used for dichotomous outcomes, OLS regressions were used for continuous outcomes, and Poisson regression was used for count outcomes when replicating Regnerus's results that used Poisson regression. All regressions used robust standard errors (White 1980).

When replicating Regnerus's (2012a) analysis in Table 3 below, I use the same control variables he used: age; race (white versus all others); gender; mother's education (five categories, including a category for missing); whether respondent recalls being bullied as a child (dichotomous); household income growing up (categorical, including a category for "don't know"); and state GLB friendliness (treated as continuous). When replicating Regnerus's results, I rely on Regnerus's definition of gay fathers (i.e., fathers who ever had a male partner) and lesbian mothers (i.e., mothers who ever had a female partner).

In Tables 4, 5, and 6 below, I modify the set of control variables to include age squared, race (five categories), mother's education (categorical, but treating missing values as missing), family-of-origin income in logged 2011 dollars, ${ }^{5}$ and family-of-origin welfare use. I dispense with state GLB friendliness as a control because most of the outcomes are not specific to year of occurrence, and state GLB friendliness changes year to year. I also dispense with having been bullied as a child as a control, because an adult's recollection of having been bullied as a child might be influenced by later events. In Tables 4 and 6, I operationalize respondent exposure to childhood family structure as the number of childhood years lived in that family structure. 
Table 2: Two Typical Life Course Profiles of Women of "Lesbian Mothers" from NFSS

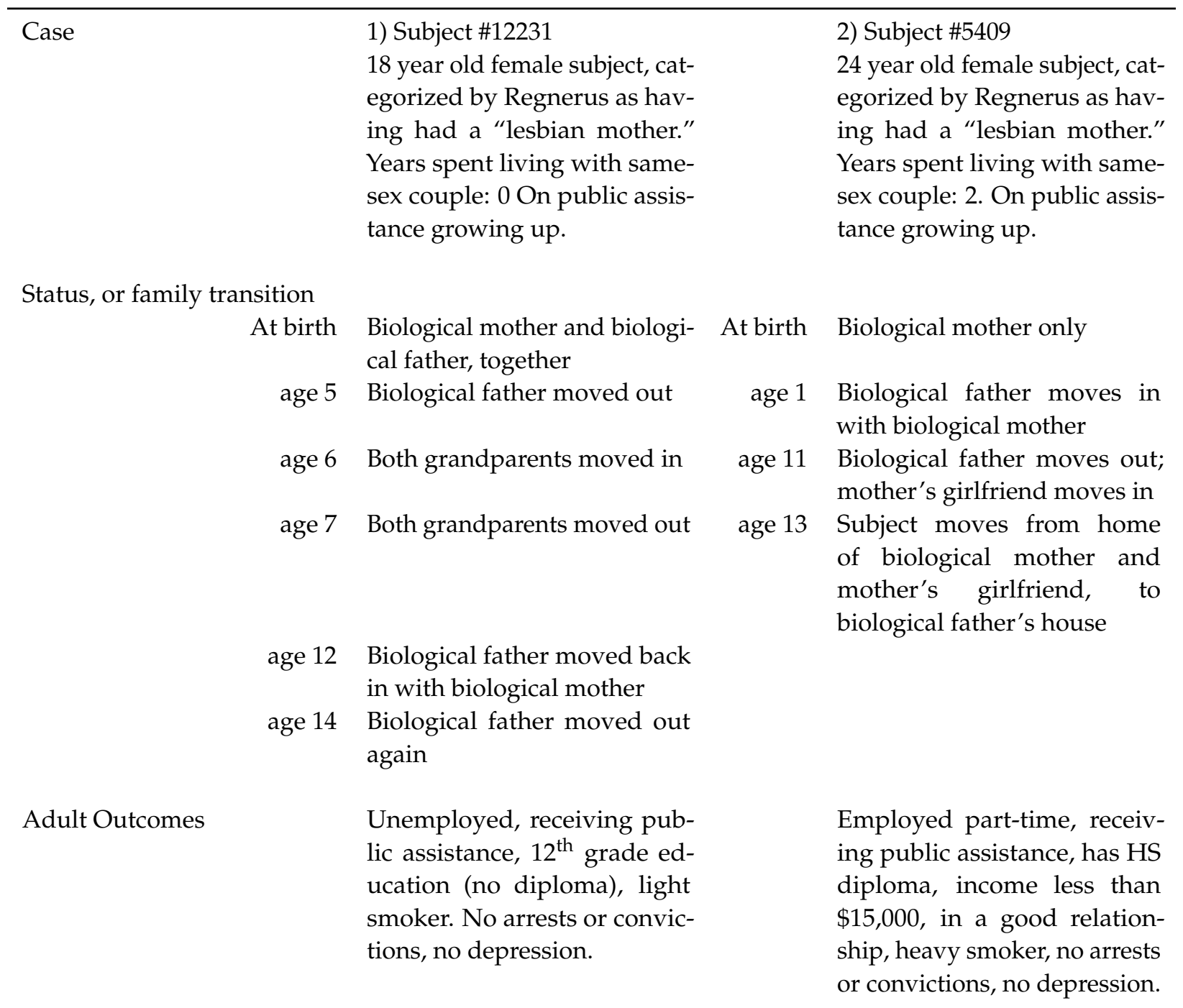

Total family transitions

Breakups of heterosexual parenting couples

Negative Index Score 


\section{Results}

\section{Part 1: Two Illustrative Life Course Trajectories}

Table 2 describes the life course of two typical NFSS subjects whose mother ever had a girlfriend, and who were therefore categorized by Regnerus as children of lesbian mothers. These two subjects also experienced more childhood family transitions than the average of 1.87. Case 1 is an 18-year-old woman who grew up on public assistance and had seven childhood family transitions. Regnerus categorized case 1 as having had a lesbian mother because her mother had a relationship with a woman at some time, yet the NFSS childhood family calendar records no instance of coresidence between this subject and her mother's girlfriend. Case 1 is similar to the majority of Regnerus's children of "lesbian mothers" and children of "gay fathers" in that they appear to have never lived with a same-sex couple. At birth, case 1 was living with her biological mother and biological father together. When the subject was age five, her biological father moved out (transition 1). When the subject was age six, her grandparents moved in (transitions 2 and 3), and at age seven the grandparents moved out (transitions 4 and 5). When the subject was 12 her biological father moved back into the house (transition 6), and then when the subject was 14 her biological father moved back out again (transition 7). Case 1 lived through two breakups of her mother and father.

Case 2 is a woman who was living with a single mother when she was an infant. When the subject was age one, her biological father moved in (transition 1) and lived with the subject for 10 years. At age 11, the subject's biological father moved out, and the mother's girlfriend moved in (transitions 2 and 3). The subject lived with same-sex couple parents for two years. At age 13, the subject moved from the home of her mother and mother's girlfriend to the home of her father (transitions 4,5 , and 6). It is important to note that parental breakups usually involve only one transition (the departure of the parent's partner from the household), whereas parental loss of custody generally involves several transitions, as the subject loses co-residence with all the adults in the household from year $\mathrm{X}$ and gains co-residence with a new set of adults in the household from year $X+1$.

Case 2 illustrates one of the fundamental challenges of studying subjects who ever lived in nontraditional families. Before case 2 ever lived with same-sex couple parents, case 2 lived with married biological parents (a heterosexual couple) for 10 years, and then lived through the breakup of her biological parents and the departure from the household of her father. Case 2 is typical of children in NFSS who ever lived with same-sex couples in that she did not start out life living with same-sex couple parents. Of the 75 NFSS subjects who ever lived with same-sex couple parents, only four were living with same-sex couple parents at birth, and the average child's age at first living with same-sex couple parents was 11 . The situation for children who ever lived with single mothers is somewhat different. Fifty-three percent of NFSS subjects who ever lived with single mothers did so before their first birthday, and the average age at first living with a single mother (for subjects who ever lived with a single mother) was 3.8 years.

The breakup of the biological parents is the canonical family transition, which has been shown to have at least a modest short-term negative impact on children 
(Wallerstein and Kelly 1980; but see also Cherlin et al. 1991). Estimates of the effect of same-sex couples on children's outcomes are nearly always confounded by the impact of the prior heterosexual relationship and its breakup. Similarly, the effect of living with a single mother on children's outcomes is often confounded with the effect on children of the single mother's prior breakups. Research that attempts to assess the outcomes of children who lived with same-sex couple parents or with single mothers without controlling for prior family disruptions as Regnerus (2012a; 2012c) did is very likely to yield biased and overly negative estimates of the association between nontraditional families and children's outcomes (see also the debate between Allen, Pakaluk, and Price 2013 and Rosenfeld 2013). The only studies that have measured outcomes for children raised by same-sex couples while avoiding the confounding effect of the breakup of prior heterosexual relationships are the studies that relied on samples of mothers who became pregnant through artificial reproductive techonology (Brewaeys et al. 1997; Chan, Raboy, and Patterson 1998).

\section{Part 2: Replication of Regnerus's Findings, With and Without Family Transitions as a Control}

The first two rows of Table 3 report summaries of regressions with controls from Regnerus (2012a, Tables 2-4); coefficients, standard errors, and further details of these regressions are in appendix Table A2. Regnerus found that subjects whose father had ever had a relationship with a male partner were significantly different on 18 out of 31 outcomes compared to children of intact biological families. Among the negative outcomes Regnerus found to be associated with subjects who had gay fathers were: more arrests; more convictions; suicidal ideation; depression; experience of having been forced into sex (at some unspecified time); lack of familyof-origin safety; and current relationship in trouble. After controlling for familyof-origin transitions (row 3 of Table 3), the number of outcomes associated with having had a father who ever had a male partner was reduced from 18 to five: suicidal ideation; depression; having had sexually transmitted infections; more female partners for female subjects; and more voting.

Regnerus's models with controls (replicated in row 2 of Table 2) showed that subjects with mothers who ever had a relationship with a woman had significantly different outcomes on 24 out of the 31 outcome variables. Regnerus (2012a) found children of lesbian mothers to be more likely to: have been sexually abused by parents or adult caregivers; ${ }^{6}$ have lower educational attainment; be more likely to have been arrested and more likely to have been convicted of major offenses; use marijuana more often; smoke more; lack attachment to others; be more likely to be depressed; and believe that their family of origin had a negative influence on their life (among many negative outcomes: see Table 3, row 2). After controlling for childhood family transitions (Table 3, row 4), children of lesbian mothers are only significantly associated with two out of 31 outcomes: less exclusive heterosexuality, and more female partners for their female children. Psychological studies of children raised by lesbian mothers have suggested that the only measurable difference between children raised by heterosexual parents and children raised by lesbian 


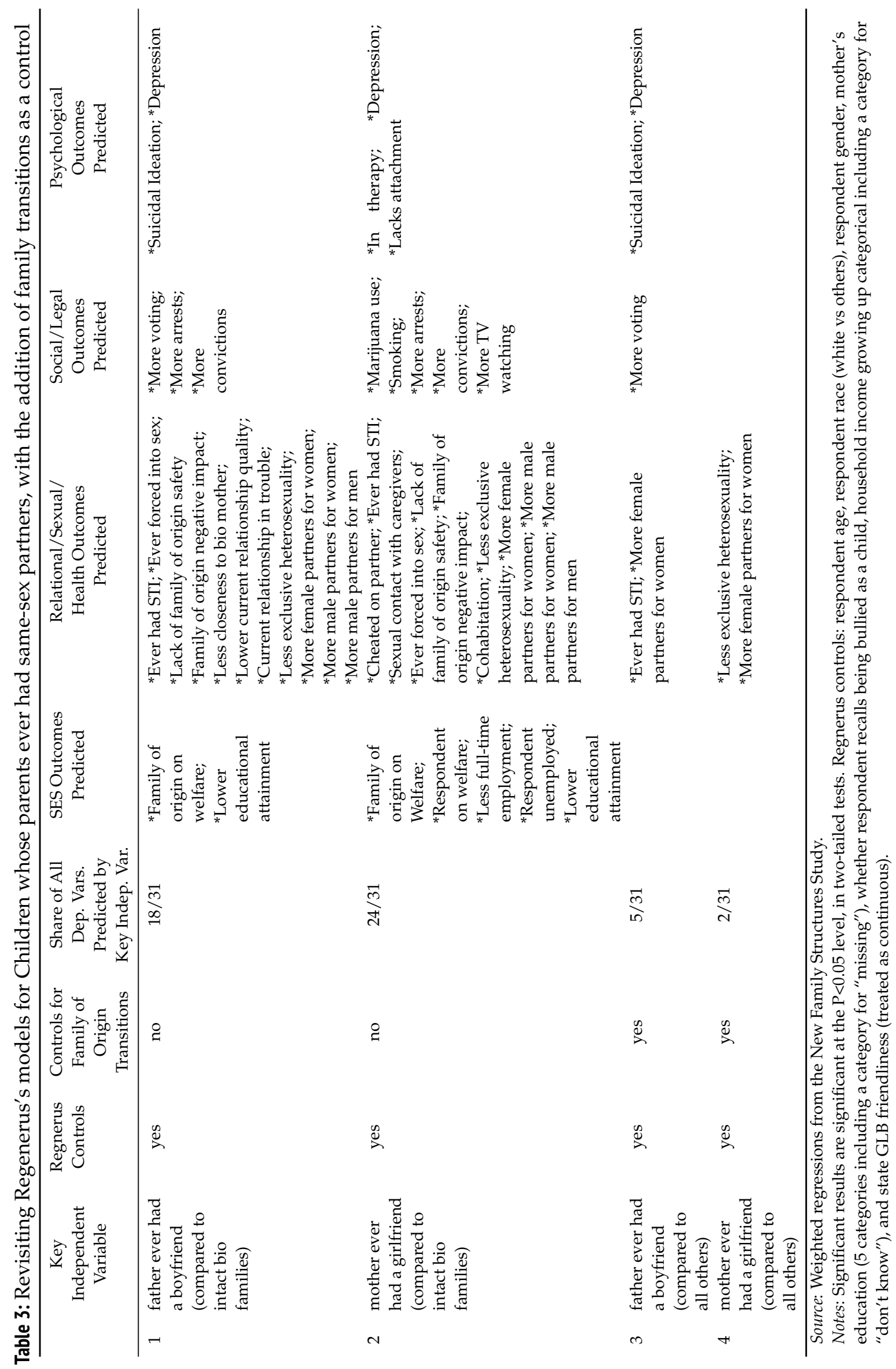




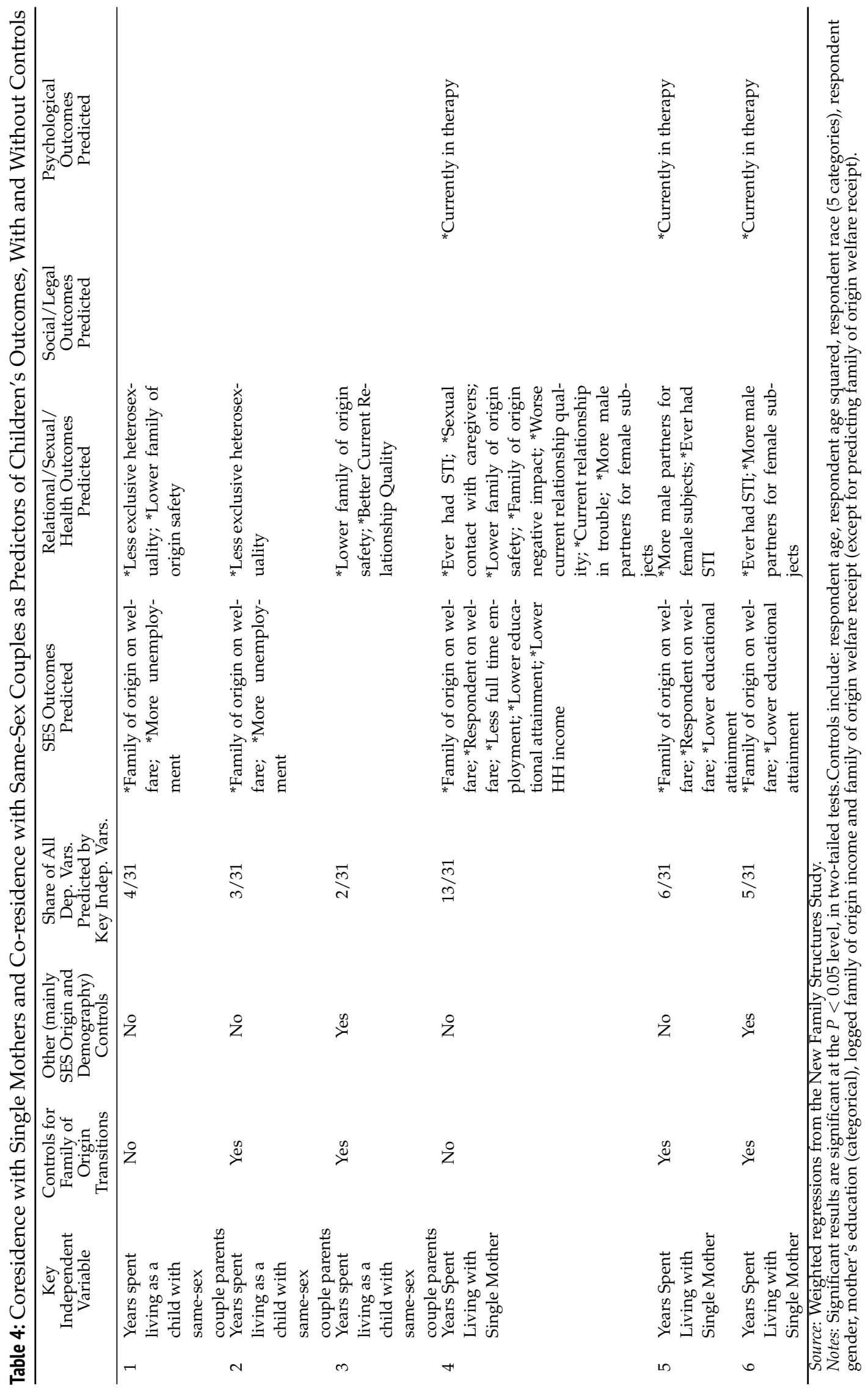


mothers is that the children raised by lesbian mothers may be less likely to be exclusively heterosexual as adults (Golombok and Tasker 1996; Stacey and Biblarz 2001).

Rows 3 and 4 of Table 3 introduce family transitions as a predictor in the models and change the comparison group from intact biological families to all other families, ${ }^{7}$ so that there is variance in family transitions in all family structure categories. Most of the negative outcomes that Regnerus attributed to lesbian mothers and to gay fathers are explained by childhood family transitions, a result which supports hypothesis 1 and is consistent with Potter's (2012) results from the Early Child Longitudinal Study.

Row 1 of Table 4 shows that childhood years lived with same-sex couples is significantly associated with only four out of 31 outcomes (for coefficients and standard errors, see Table A3 in the appendix). Controlling for childhood family transitions and family-of-origin socioeconomic status (row 3 ) results in years lived with same-sex couple parents being significantly associated with only two outcomes: one positive (better current relationship quality) and one negative (lower sense that the family of origin was safe).

One potential critique of the lack of significance of effects of lesbian mother, gay father, or years lived with same-sex couples on children is that the number of such families (and the years lived with same-sex couples) is small, and the statistical power is therefore correspondingly weak to reject null hypotheses. Rows 4, 5, and 6 of Table 4 consider the more common family structure of years lived with single mothers. Of the 2,988 subjects in the NFSS data, only 75 ever lived with same-sex couple parents, whereas 1,296 NFSS subjects lived at least one year with single mothers.

Years spent living with single mothers are associated with 13 significant outcomes, including: lower subject socioeconomic status (respondent on welfare, less employment, lower educational attainment); and a variety of sexual and health outcomes including sexual contact with parents or adult caregivers, sexually transmitted infections, family-of-origin negative impact, and current relationships in trouble, along with the psychological outcome of being in therapy. Controlling for childhood family transitions reduces the number of significant outcomes associated with years spent living with single mothers from 13 to six, thus supporting hypothesis 2 , that family transitions would mediate the apparent negative outcomes associated with single parenthood. After controlling for children's socioeconomic background, years spent living with single mothers are associated with five outcomes: increased family-of-origin welfare use (not surprising because the implementation of welfare in the past was designed to support single mothers and their children); lower subject educational attainment; sexually transmitted infections; more male partners for female subjects; and greater likelihood of being in therapy.

Childhood family transitions are associated with negative children's outcomes across every outcome type into adulthood. Row 1 of Table 5 shows that childhood transitions are significantly associated with 30 out of 31 outcomes. Family transitions significantly predict every negative outcome and all of the ambiguous outcomes except for the number of male sexual partners for male respondents. Row 2 of Table 5 shows that family transitions are significantly associated with 21 of the 


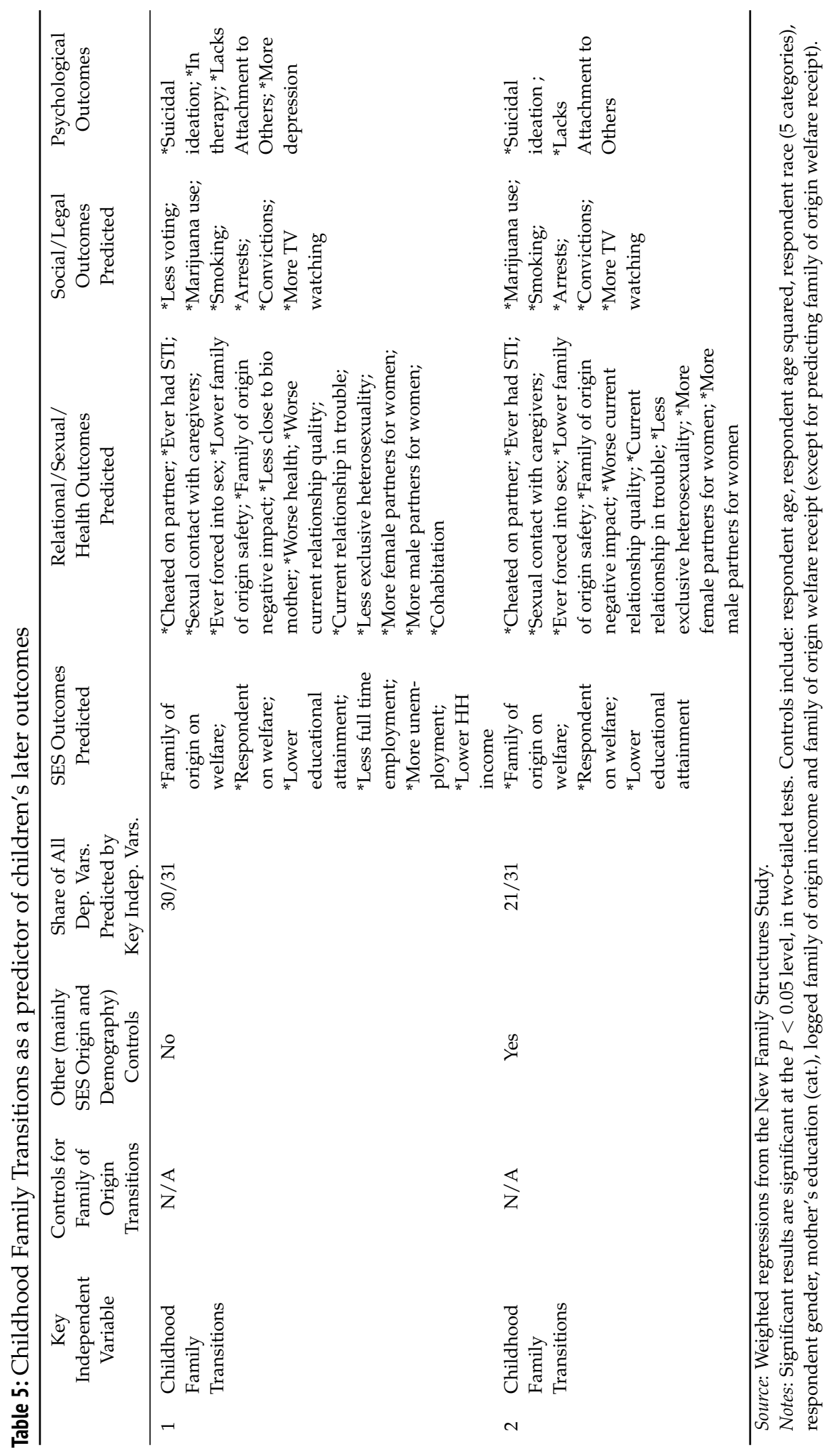


31 outcome variables, after controls for demographic background are applied. The strong association of childhood family transitions on negative outcomes in Table 5 supports hypothesis 3 , that childhood family transitions would have a strong and significant impact on adult outcomes, even after controlling for socioeconomic background.

The summaries of regressions predicting 31 outcomes in Tables 3, 4, and 5 might be a little misleading, because in a large enough set of outcomes some predictors would be expected to be significant just by chance, even in the absence of an underlying relationship between dependent and independent variables (Freedman 1983). Furthermore, the five percent cutoff for significance is arbitrary, and because Tables 3, 4, and 5 ignore the values of coefficients in question, much information is lost. In Table 6, I show how well each of the key predictors predicts the negative outcome index (a standardized combination of 19 negative outcomes with mean zero and standard deviation of one), with and without controls. The negative outcome index summarizes outcomes across a range of categories.

Model 1 of Table 6 shows that years lived with single mothers are significantly associated with a higher negative outcome index. The coefficient for years lived with single mothers in model 1 is 0.022 , meaning that an additional 10 years of living with a single mother would increase the negative outcome index by 0.22 , or just under one quarter of one standard deviation in the negative outcome index. The R-square of model 1 is small, however-less than two percent.

Model 2 shows that once family transitions are added into the model, the coefficient for years lived with a single mother drops from 0.022 to 0.011 and is no longer statistically significant. The way that family transitions mediate the association apparent in model 1 between negative outcomes and years spent living with a single mother supports hypothesis 2 and fulfills the requirements of a formal mediation test of the Baron and Kenny (1986) type (along with the association between years lived with single mothers and family transitions, which is significant but not shown).

Model 3 uses the log of family transitions rather than the untransformed count of family transitions (which had positive outliers). Model 3 fits significantly less well than model 2 by the BIC criteria for comparing non-nested models (using Raftery's 1995 formula BIC $=n \log \left(1-R^{2}\right)+p \ln (n)$, where $\mathrm{n}$ is the sample size of the data and $\mathrm{p}$ is the number of terms in the model excluding the constant). The more negative the BIC score, the better the fit of the model. The BIC difference between models 2 and 3 corresponds to a $\mathrm{P}$ value of less than $10^{-8}$ that model 3 fits better; therefore the untransformed version of family transitions is preferred.

Model 4 substitutes the narrow definition of family transitions, counting only the breakups of heterosexual couples. Model 2 fits dramatically better than model 4, with a BIC difference of -237 , corresponding to a P value of less than $10^{-50}$, meaning that we are certain that the full set family transitions predicts negative outcomes better than the narrow definition of family transitions. Figure 2 shows that many different types of family transitions are associated with the negative outcome index to a similar extent, which supports the view that childhood family transitions of many types are similarly associated with negative adult outcomes. ${ }^{8}$ 


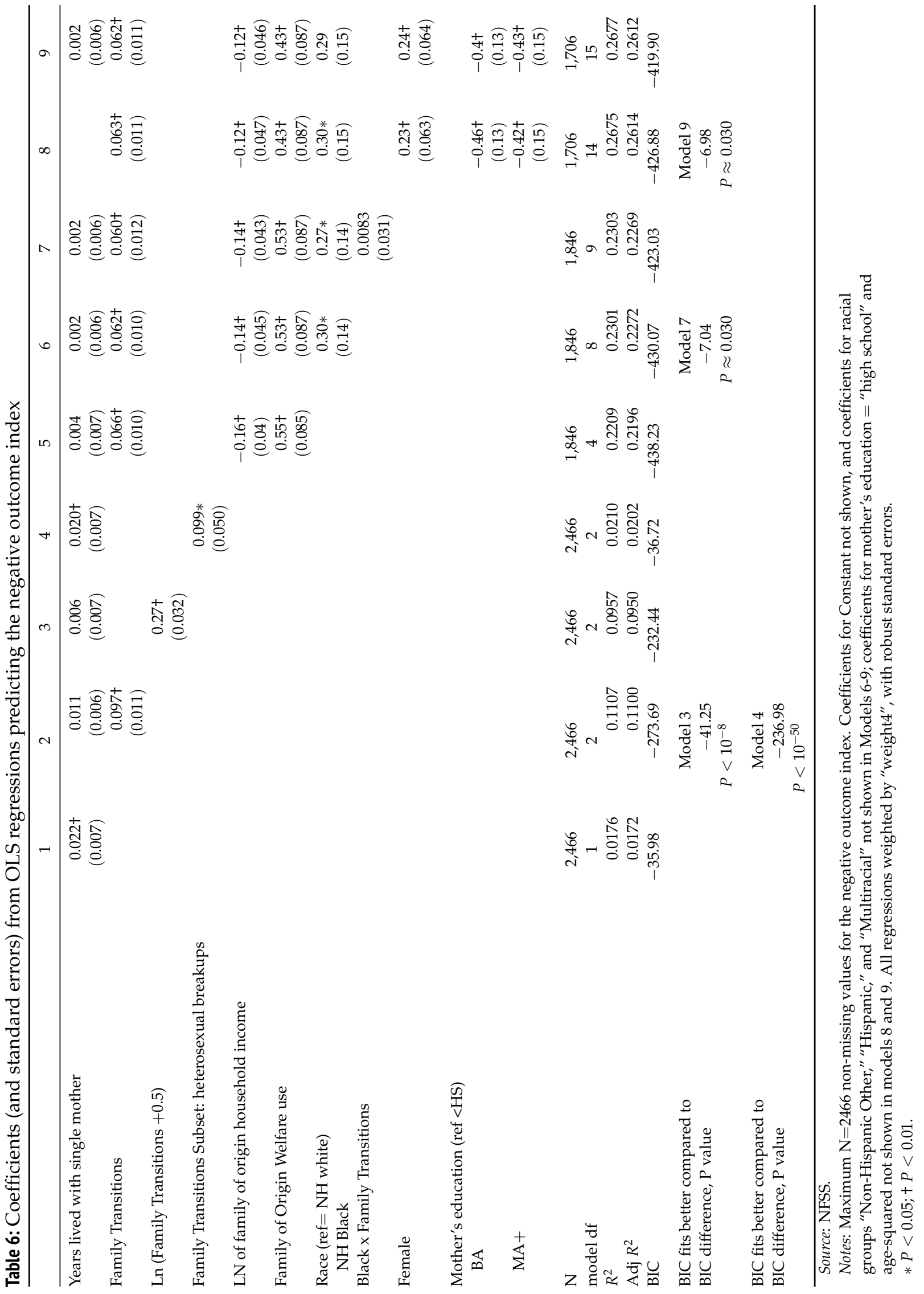




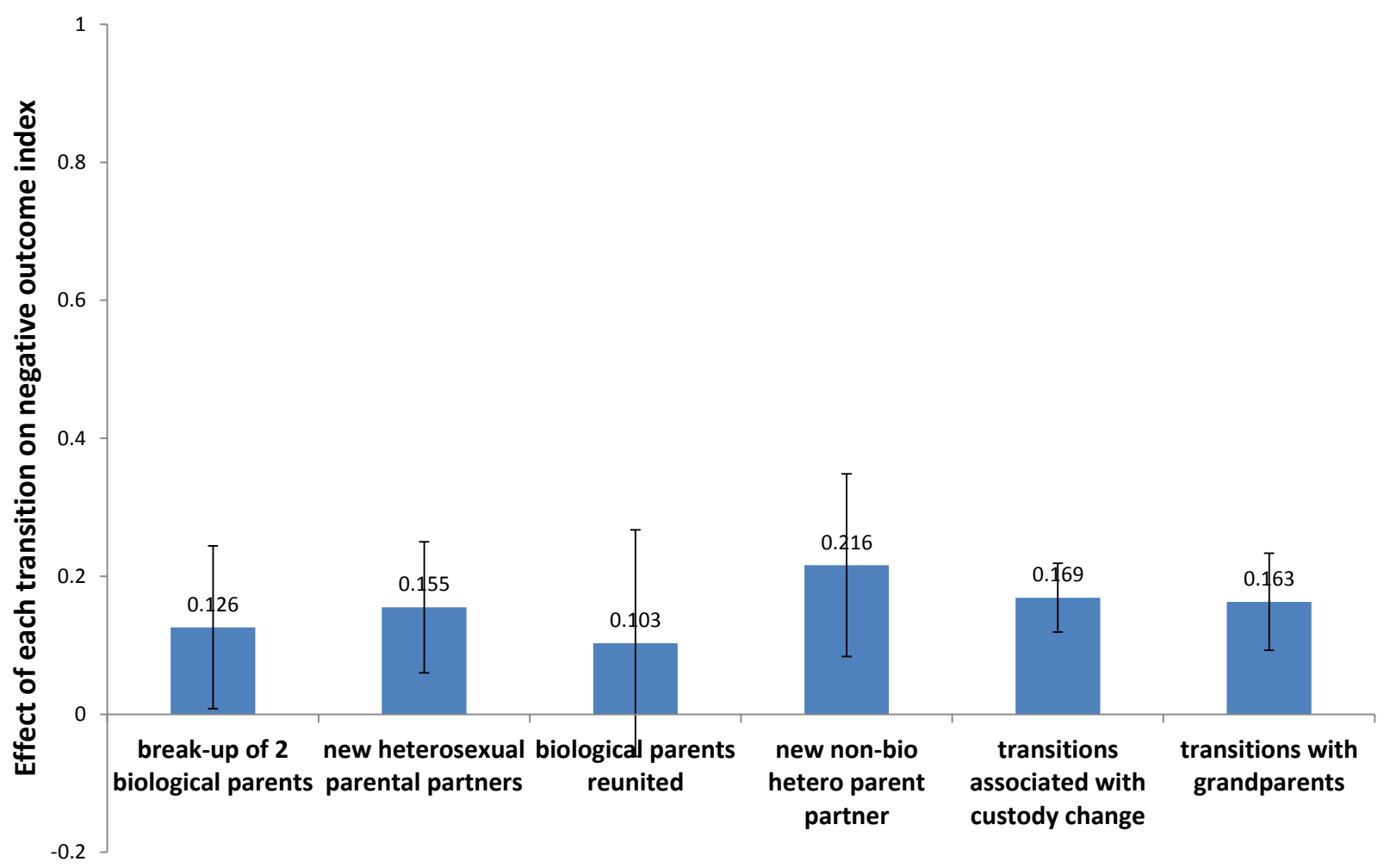

Figure 2: Different Types of Family Transitions as Predictors of the Standardized Negative Outcome Index, with $95 \%$ Confidence Intervals

Data Source: NFSS. Coefficients from OLS regressions are weighted by variable "weight4" as the probability weight, with robust standard errors, $\mathrm{N}=2,466 * \mathrm{P}<0.05 ; * * \mathrm{P}<0.01 ; * * * \mathrm{P}<0.001$, two-tailed tests.

The addition of family-of-origin income and family-of-origin welfare use in model 5 further diminishes the already insignificant coefficient for years lived with a single mother. Family transitions remains a strongly significant predictor of negative outcomes across all models in Table 6, which supports hypothesis 3 and corollary $3 \mathrm{a}$, that family transitions would be a strong and significant predictor of negative outcomes regardless of what controls are included in the models (a result also confirmed by Table 5, above). The comparison of models 6 and 7 shows that the association between family transitions and negative outcomes is the same for black and white subjects in the NFSS, which is different from what prior research has shown in other datasets (Fomby and Cherlin 2007; Wu and Thomson 2001). The comparison of models 8 and 9 shows that in the NFSS data (with its substantial limitations as a retrospective dataset), years lived with a single mother do not predict the negative outcome index at all after family transitions and demographic background are accounted for.

Table A5 in the appendix revisits the models from Table 6, with multiple imputation replacing missing values of predictors and replacing missing values of the negative outcome index. Consistent with Table 6, the results from Table A5 show that when family transitions and background demography are accounted for, none 
of the family structure exposures (years lived with single mothers, years lived with both biological parents, years lived with same-sex couples) significantly predict negative outcomes in the NFSS.

\section{Part 3: The Relevance of Different Types of Family Transitions}

Table 7 shows the cumulative number of family transitions broken into subcategories for NFSS subjects who never lived with a same-sex couple (column A) and those who did live with a same-sex couple (column B), and subjects who never lived with a single mother (column C) and subjects who did live with a single mother (column D). Adults who ever lived with same-sex couple parents experienced an average of 6.79 family transitions, while adults who never lived with same-sex couple parents experienced 1.84 childhood family transitions, a difference of almost five transitions between the two groups. Among all NFSS subjects, six was the $90^{\text {th }}$ percentile of the weighted distribution for family transitions, and seven was the $92^{\text {nd }}$ percentile.

Counter-hypothesis 4 presumes that the instability of same-sex romantic unions explained or accounted for the higher level of family transitions among children raised by same-sex couples. Table 7 shows, however, that of the almost fivetransition difference between columns A and B, less than half of one transition, or 0.41 transitions per subject, is accounted for by breakups of same-sex couples. The single largest contributor to the family transitions gap between children raised by same-sex couples and children not raised by same-sex couples is the difference in transitions resulting from a biological parent losing custody. Children who ever lived with same-sex couple parents experienced an average of 2.67 transitions due to parental loss of custody, while children who never lived with same-sex couple parents experienced only 0.41 transitions, on average, due to parental loss of custody. As I noted above in my discussion of Table 2, the typical custody change involves three or four transitions at once. Additional analyses (see appendix Table A6) show that the chance of losing custody in any given year was less than one percent for mothers partnered with men (including the biological father of the child), and more than 11 percent for mothers partnered with women.

\section{Conclusion}

The NFSS data and the same 31 outcomes (but without controls for family instability) have been used to argue for the power of family structure over children's outcomes, and more specifically to suggest that gay and lesbian parents are associated with poor children's outcomes (Regnerus 2012a; Regnerus 2012c). My replication of Regnerus's models shows that a simple control for family transitions accounts for most of the negative outcomes for subjects who had "gay fathers" or "lesbian mothers." The analysis here represents the first empirical support for the argument by early critics (Burroway 2012; Gates 2012; Umberson 2012) that Regnerus's (2012a) analysis was flawed by his failure to control for childhood family instability.

My analyses add to the growing body of literature that finds that family-oforigin instability is a crucial independent factor in explaining children's outcomes 


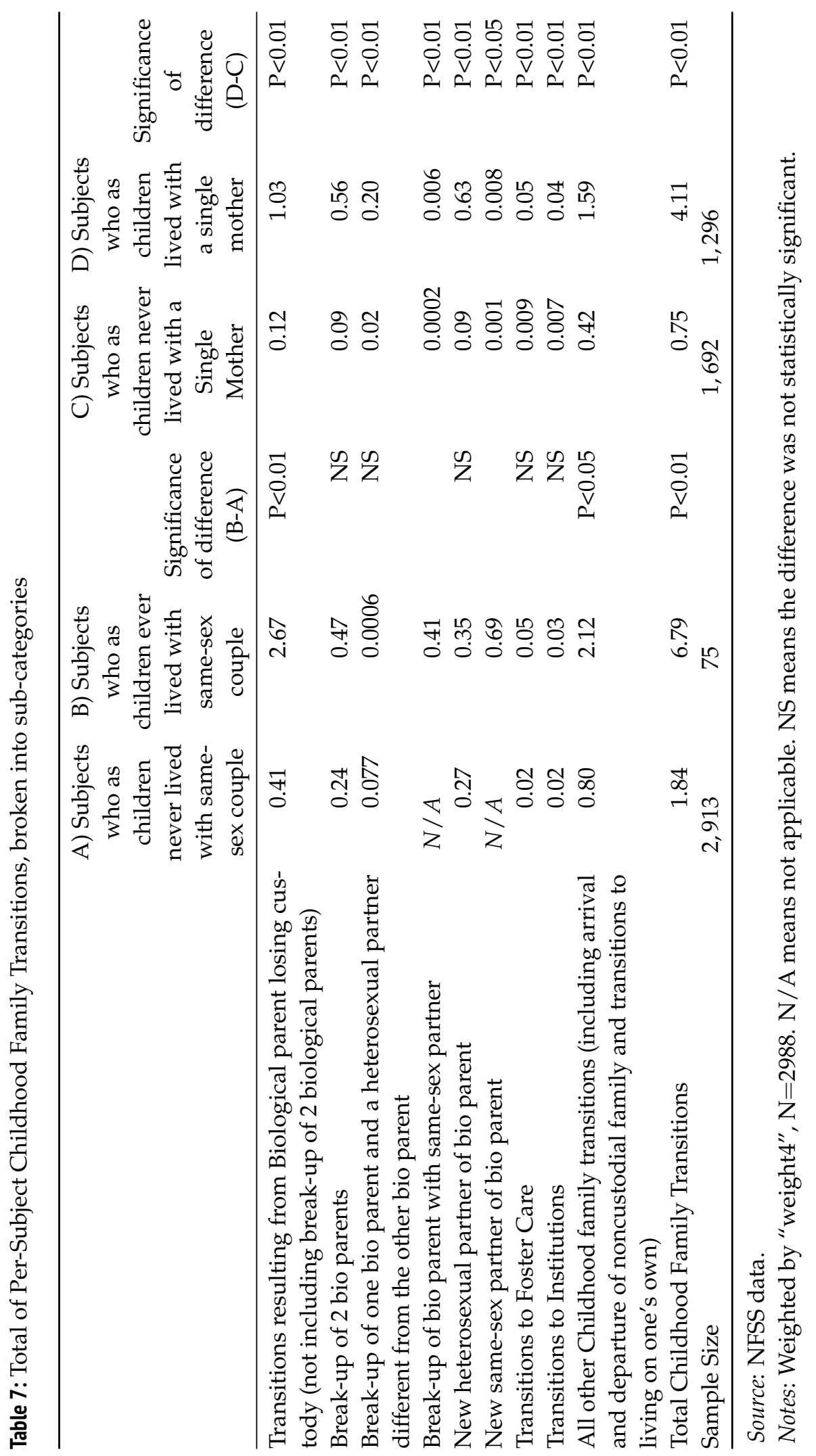


(Fomby and Cherlin 2007; Manning and Lamb 2003; Kurdek, Fine, and Sinclair 1995; Wu and Martinson 1993). I show that a broad definition of family transitions has more explanatory power than the narrow definition of family transitions that has been typically used in the past. Various different kinds of family transitions, from the canonical breakup of the biological parent couple to the arrival of a single parent's new partner, to the presumably innocuous grandparent moving into the home, all are similarly associated with negative adult outcomes.

One important limitation of my analyses is that the causes and correlates of individual family transitions in the NFSS are not known. Research using longitudinal data has divergent findings about whether family transitions such as parental divorce have a measurable effect on children net of measured and unmeasured family characteristics that might be associated with the divorce (Aughinbaugh, Pierret, and Rothstein 2005; Fomby and Cherlin 2007).

Regnerus (2012c) and Allen, Pakaluk, and Price (2013) have argued that samesex couples are inherently unstable, and that therefore couple instability and family instability are pathways through which the children of same-sex couples come to have poor outcomes. The NFSS data show that custody loss rather than breakups of same-sex couples explain the high rate of family transitions experienced by children who ever lived with same-sex couples. Although the NFSS data do not provide any clues as to why mothers with same-sex partners so often lost custody of their children, literature on family law documents a strong bias against gay and lesbian parents in judicial custody decisions in the past (Wald 2006). Furthermore, the most recent research on same-sex couples in committed relationships shows that same-sex couples and heterosexual couples in committed relationships are similarly stable (Ross, Gask, and Berrington 2011; Rosenfeld 2014).

\section{Notes}

1 NFSS question S7: "From when you were born until age 18 (or until you left home to be on your own), did either of your parents ever have a romantic relationship with someone of the same sex?"

2 Of the childhood years lived by all NFSS subjects in the 1972-2012 period, only 0.11 percent of the childhood years were lived with same-sex couples.

3 The 13 potential household members in the NFSS childhood family calendar were: Biological Mother; Biological Father; Stepmother; Stepfather; Mother's Boyfriend; Father's Girlfriend; Adoptive Mother; Adoptive Father; Grandmother; Grandfather; and Other Relative, along with two categories used for the determination of living with same-sex couples (Mother's Girlfriend and Father's Boyfriend).

4 Cheng and Powell (2015) note that NFSS subjects who indicated that their biological parents had been married and had lived together throughout the subject's childhood and were still together years later (the family structure Regnerus referred to as "Intact Biological Family") did not see questions about whether the parents ever had a samesex relationship and did not see the childhood family calendar. Therefore they could not record whether other types of childhood family transitions (such as transition to cohabitation with grandparents or other relatives) ever took place. The children of "Intact Biological Families" are constrained in NFSS to have exactly zero childhood 
family transitions, which for some respondents must represent an underreporting of the true number of childhood family transitions.

5 NFSS question S35 about family-of-origin income reads, "While growing up, many children and teens become aware, if only vaguely, of their family's approximate annual household income. Thinking back to when you were a teenager, would you say your family's income was...," and appears to have resulted in subjects putting their past family income roughly into current (2011) dollars, as the recalled household income is appropriately flat with respect to subject age, but correcting for inflation (which was not done) would make the older respondents appear to come from substantially more well-to-do backgrounds.

6 Regnerus's Table 2 suggested that children raised by lesbian mothers and children raised by gay fathers had relatively high rates of reporting sexual abuse by parents or guardians, but recall that Regnerus's categories of "lesbian mothers" and "gay fathers" were not based on same-sex couple coresidence with children. Of the 31 abused respondents who were categorized by Regnerus as having been raised by "lesbian mothers," only three were living with their biological mother and mother's girlfriend when the abuse started. Of the 12 abused respondents whom Regnerus categorized as having been raised by "gay fathers," none was living with father and father's boyfriend when the abuse started.

7 For the intermediate results from changing the comparison group but before introducing family transitions as a control, see Table A2 in the appendix. Because Regnerus's category of "intact biological families" was constrained to have zero reported family transitions, collinearity prevents the family transition control from being used in combination with the "intact biological family" family structure comparison category.

8 Not shown in Figure 2 are the less common transitions to foster care and to institutional living. Each transition to foster care was associated with a negative outcome index increase of 1.44. Each transition to institutional living raised the negative outcome index by 1.22. See also Rosenfeld (2010) on the difference between family structures and institutional structures in children's outcomes.

\section{References}

Allen, Douglas W., Catherine Pakaluk, and Joseph Price. 2013. "Nontraditional Families and Childhood Progress Through School: A Comment on Rosenfeld." Demography 50(3):955961. http://dx.doi.org/10.1007/s13524-012-0169-x.

Alvaré, Helen M. 2005. "The Turn Toward the Self in the Law of Marriage And Family: Same-Sex Marriage and its Predecessors." Stanford Law and Policy Review 16(1):135-196.

American Association for Public Opinion Research. 2011. "Standard Definitions: Final Dispositions of Case Codes and Outcome Rates for Surveys." http://www.aapor. org/AM/Template.cfm?Section $\$=\$$ Standard_Definitions $2\{\&\}$ Template $\$=\$ / C M /$ ContentDisplay . $\operatorname{cfm}\{\&\}$ ContentID $\$=\$ 3156$.

Aughinbaugh, Alison, Charles R. Pierret, and Donna S. Rothstein. 2005. "The Impact of Family Structure Transitions on Youth Achievement: Evidence from the Children of the NLSY79." Demography 42(3):447-468. http: //dx. doi .org/10.1353/dem. 2005.0023.

Baron, Reuben M. and David A. Kenny. 1986. "The Moderator-Mediator Variable Distinction in Social Psychological Research: Conceptual, Strategic, and Statistical Considerations." Journal of Personality and Social Psychology 51(6):1173-1182. http://dx . doi .org/10 . 1037/ 0022-3514.51.6.1173. 
Brewaeys, A., I. Ponjaert, E.V. Van Hall, and S. Golombok. 1997. "Donor Insemination: Child Development and Family Functioning in Lesbian Mother Families." Human Reproduction 12(6):1349-1359. http://dx.doi.org/10.1093/humrep/12.6.1349.

Brody, Gene H., Eileen Neubaum, and Rex Forehand. 1986. "Serial Marriage: A Heuristic Analysis of an Emerging Family Form." Psychological Bulletin 103(2):211-222. http://dx . doi.org/10.1037/0033-2909.103.2.211.

Burroway, Jim. 2012. "First Look at Mark Regnerus's Study on Children of Parents in SameSex Relationships." Box Turtle Bulletin. http://www . boxturtlebulletin. com/2012/06/ $10 / 45512$.

Callegaro, Mario and Charles DiSogra. 2008. "Computing Response Metrics for Online Panels." Public Opinion Quarterly 72(5):1008-1032. http://dx.doi.org/10.1093/poq/ nfn065.

Carlson, Marcia J. and Mary E. Corcoran. 2001. "Family Structure and Children's Behavioral and Cognitive Outcomes." Journal of Marriage and Family 63(3):779-792. http://dx . doi . org/10.1111/j.1741-3737.2001.00779.x.

Cavanagh, Shannon E. 2008. "Family Struture History and Adolescent Adjustment." Journal of Family Issues 29(7):944-980. http: //dx. doi . org/10 . 1177/0192513X07311232.

Cavanagh, Shannon E. and Aletha C. Huston. 2006. "Family Instability and Children's Early Problem Behavior." Social Forces 85(1):551-581. http://dx . doi .org/10.1353/sof . 2006. 0120.

Chan, Raymond W., Barbara Raboy, and Charlotte J. Patterson. 1998. "Psychosocial Adjustment among Children Conceived via Donor Insemination by Lesbian and Heterosexual Mothers." Child Development 69(2):443-457. http://dx.doi.org/10.1111/j.1467-8624. 1998.tb06201.x,

Chang, Linchiat and Jon A. Krosnick. 2009. "National Surveys via RDD Telephone Interviewing versus the Internet: Comparing Sample Representativeness and Response Quality." Public Opinion Quarterly 73(4):661-674. http://dx.doi .org/10.1093/poq/nfp075.

Cheng, Simon and Brian Powell. 2015. "Measurement, Methods, and Divergent Patters: Reassessing the effects of Same-Sex Parents." Social Science Research 52:615-626. http: //dx.doi.org/10.1016/j.ssresearch.2015.04.005.

Cherlin, Andrew J. 1978. "Remarriage as an Incomplete Institution." American Journal of Sociology 84(3):634-650. http://dx. doi .org/10.1086/226830.

Cherlin, Andrew J., Frank F. Furstenberg, Jr., P. Lindsay Chase-Lansdale, Kathleen E. Kiernan, Philip K. Robins, Donna Ruane Morrison, and Julien O. Teitler. 1991. "Longitudinal Studies of Effects of Divorce on Children in Great Britain and the United States." Science 252:1386-1389. http://dx.doi.org/10.1126/science. 2047851.

Couper, Mick P. 2000. "Web Surveys: A Review of Issues and Approaches." Public Opinion Quarterly 64:464-494. http://dx.doi.org/10.1086/318641.

Fomby, Paula and Andrew J. Cherlin. 2007. "Family Instability and Child WellBeing." American Sociological Review 72(2):181-204. http://dx.doi.org/10.1177/ 000312240707200203.

Freedman, David A. 1983. "A Note on Screening Regression Equations." The American Statistician 37(2):152-155. http://dx . doi .org/10.2307/2685877.

Fricker, Scott, Mirta Galesic, Roger Tourangeau, and Ting Yan. 2005. "An Experimental Comparison of Web and Telephone Surveys." Public Opinion Quarterly 69(3):370-392. http://dx.doi.org/10.1093/poq/nfi027. 
Gates, Gary J. 2009. "Same-Sex Spouses and Unmarried Partners in the American Community Survey, 2008." The Williams Institute. http://williamsinstitute. law.ucla.edu/ wp-content/uploads/Gates-ACS2008FullReport-Sept-2009.pdf.

Gates, Gary J. 2012. "Letter to the Editors and Advisory Editors of Social Science Research." Social Science Research 41(6):1350-1351. http://dx . doi .org/10.1016/j . ssresearch. 2012. 08.008.

Golombok, Susan and Fiona Tasker. 1996. "Do Parents Influence the Sexual Orientation of Their Children? Findings from a Longitudinal Study of Lesbian Families." Developmental Psychology 32(1):3-11. http: //dx. doi .org/10.1037/0012-1649.32.1.3.

Hunter, James E. and Nancy Schuman. 1980. "Chronic Reconstitution as a Family Style." Social Work 25:446-451.

Kalton, Graham and Ismael Flores-Cervantes. 2003. "Weighting Methods." Journal of Official Statistics 19(2):81-97.

Kurdek, Lawrence A., Mark A. Fine, and Ronald J. Sinclair. 1995. "School Adjustment in Sixth Graders: Parenting Transitions, Family Climate, and Peer Norm Effects." Child Development 66(2):430-445. http://dx. doi .org/10.2307/1131588.

Manning, Wendy D. and Kathleen A. Lamb. 2003. "Adolescent Well-Being in Cohabiting, Married, and Single-Parent Families." Journal of Marriage and Family 65:876-893. http: //dx.doi.org/10.1111/j.1741-3737.2003.00876.x.

McLanahan, Sara and Gary Sandefur. 1994. Growing Up with a Single Parent: What Hurts, What Helps. Cambridge, MA: Harvard University Press.

Meezan, William and Jonathan Rauch. 2005. "Gay Marriage, Same-Sex Parenting, and America's Children." The Future of Children 15(2):97-115. http://dx . doi .org/10.1353/ foc. 2005.0018.

Perrin, Andrew J., Philip N. Cohen, and Neal Caren. 2013. "Responding to the Regnerus Study: Are Children of Parents who had Same-Sex Relationships Disadvantaged? A Scientific Evaluation of the No-Differences Hypothesis." Journal of Gay E Lesbian Mental Health 17:327-336. http://dx.doi.org/10.1080/19359705.2013.772553.

Potter, Daniel. 2012. "Same-Sex Parent Families and Children's Academic Achievement." Journal of Marriage and Family 74:556-571. http://dx . doi .org/10.1111/j .1741-3737. 2012.00966.x.

Raftery, Adrian E. 1995. "Bayesian Model Selection in Social Research." Sociological Methodology 25:111-163. http://dx.doi .org/10.2307/271063.

Regnerus, Mark. 2012a. "How Different are the Adult Children of Parents who have Same-Sex Relationships? Findings from the New Family Structures Study." Social Science Research 41:752-770. http://dx.doi.org/10.1016/j.ssresearch.2012.03.009.

Regnerus, Mark. 2012b. "New Family Structures Study." Inter-university Consortium for Political and Social Research. www.icpsr.umich.edu. http://dx.doi.org/10.3886/ ICPSR34392.v1.

Regnerus, Mark. 2012c. "Parental Same-Sex Relationships, Family Instability, and Life Outcomes for Adult Children: Answering Critics of the New Family Structures Study with Additional Analyses." Social Science Research 41:1367-1377. http://dx. doi .org/10. 1016/j.ssresearch.2012.08.015.

Regnerus, Mark. 2013. "Expert Report in DeBoer v. Snyder." http://web.stanford.edu/ rmrosenfe/DeBoer_affidavits/defense/Regnerus.pdf.

Rosenfeld, Michael J. 2010. "Nontraditional Families and Childhood Progress Through School." Demography 47(3):755-775. http: //dx.doi.org/10.1353/dem.0.0112. 
Rosenfeld, Michael J. 2013. "Reply to Allen et al." Demography 50(3):963-969. http://dx. doi . org/10.1007/s13524-012-0170-4.

Rosenfeld, Michael J. 2014. "Couple Longevity in the Era of Same-Sex Marriage in the US." Journal of Marriage and Family 76:905-918. http://dx . doi .org/10.1111/jomf .12141.

Ross, Helen, Karen Gask, and Ann Berrington. 2011. "Civil Partnerhsip Five Years On." Population Trends 145(1):172-202. http://dx.doi.org/10.1057/pt.2011.23.

Stacey, Judith and Timothy J. Biblarz. 2001. "(How) Does the Sexual Orientation of Parents Matter?" American Sociological Review 66(2):159-183. http://dx . doi .org/10 . 2307/ 2657413.

Umberson, Debra. 2012. "Texas Professors Respond to New Research on Gay Parenting." Huffington Post. http://www.huffingtonpost.com/debra-umberson/ texas-professors-gay-research_b_1628988.html.

Wald, Michael. 2006. "Adults' Sexual Orientation and State Determinations Regarding Placement of Children." Family Law Quarterly 40:385-439. http://dx . doi .org/10 . 2139/ ssrn.920670.

Wallerstein, Judith S. and Joan Berlin Kelly. 1980. Surviving the Breakup: How Children and Parents Cope with Divorce. New York: Basic Books.

White, Halbert. 1980. "A Heteroskedasticity-Consistent Covariance Matrix Estimator and a Direct Test for Heteroskedasticity." Econometrica 48:817-830. http://dx. doi .org/10. $2307 / 1912934$.

Wu, Lawrence L. 1996. "Effects of Family Instability, Income and Income Instability on the Risk of a Premarital Birth." American Sociological Review 61(3):386-406. http://dx. doi. org/10.2307/2096355.

Wu, Lawrence L. and Brian C. Martinson. 1993. "Family Structure and the Risk of a Premarital Birth." American Sociological Review 58(2):210-232. http://dx . doi .org/10. 2307/ 2095967.

Wu, Lawrence L. and Elizabeth Thomson. 2001. "Race Differences in Family Experience and Early Sexual Initiation: Dynamic Models of Family Structure and Family Change." Journal of Marriage and Family 63(3):682-696. http://dx.doi .org/10.1111/j.1741-3737.2001. 00682.x.

Acknowledgements: Helpful advice on previous drafts was offered by Kate Weisshaar and Maja Falcon, Ariela Schachter, Soomin Kim, the Family Sociology workshop at Stanford, and the editors of Sociological Science. The author is grateful to Simon Cheng for assistance in replicating Regnerus's models and for sharing analyses behind Cheng and Powell's 2015 paper.

Michael J. Rosenfeld: Department of Sociology, Stanford University. E-mail: mrosenfe@stanford.edu. 